\title{
MOLECULAR BIO-DOSIMETRY FOR CARCINOGENIC RISK ASSESSMENT IN SURVIVORS OF BHOPAL GAS TRAGEDY
}

\author{
PRADYUMNA KUMAR MISHRA ${ }^{1,2,3}$, GORANTLA VENKATA RAGHURAM ${ }^{1,2,3}$, NEHA BUNKAR $^{1}$, \\ ARPIT BHARGAVA ${ }^{1,2,3}$, and NAVEEN KUMAR KHARE ${ }^{2,3}$
}

${ }^{1}$ Dr. H. S. Gour Central University, Sagar, India

Translational Research Lab, School of Biological Sciences

${ }^{2}$ Tata Memorial Centre, Advanced Centre for Treatment, Research and Education in Cancer, Navi Mumbai, India

Division of Translational Research

${ }^{3}$ Bhopal Memorial Hospital and Research Centre, Bhopal, India

Department of Research and Training

\begin{abstract}
December 2014 marked the 30th year anniversary of Bhopal gas tragedy. This sudden and accidental leakage of deadly poisonous methyl isocyanate (MIC) gas instigated research efforts to understand the nature, severity of health damage and sufferings of 570000 ailing survivors of this tragedy. In a decade-long period, our systematic laboratory investigations coupled with long-term molecular surveillance studies have comprehensively demonstrated that the risk of developing an environmental associated aberrant disease phenotype, including cancer, involves complex interplay of genomic and epigenetic reprogramming. These findings poised us to translate this knowledge into an investigative framework of "molecular biodosimetry" in a strictly selected cohort of MIC exposed individuals. A pragmatic cancer risk-assessment strategy pursued in concert with a large-scale epidemiological study might unfold molecular underpinnings of host-susceptibility and exposureresponse relationship. The challenges are enormous, but we postulate that the study will be necessary to establish a direct initiation-promotion paradigm of environmental carcinogenesis. Given that mitochondrial retrograde signaling-induced epigenetic reprogramming is apparently linked to neoplasticity, a cutting-edge tailored approach by an expert pool of biomedical researchers will be fundamental to drive these strategies from planning to execution. Validating the epigenomic signatures will hopefully result in the development of biomarkers to better protect human lives in an overburdened ecosystem, such as India, which is continuously challenged to meet population demands. Besides, delineating the mechanistic links between MIC exposure and cancer morbidity, our investigative strategy might help to formulate suitable regulatory policies and measures to reduce the overall burden of occupational and environmental carcinogenesis.
\end{abstract}

Key words:

Biomarkers, Occupational health, Methyl isocyanate, Cancer risk, Environmental medicine, Translational oncology

The studies were supported in part by Department of Biotechnology Grant (BT/PR13133/GBD/27/201/2009), Government of India, New Delhi. Principal investigator: Pradyumna K. Mishra, Ph.D.

Received: April 28, 2014. Accepted: January 24, 2015.

Corresponding author: P.K. Mishra, Translational Research Lab, School of Biological Sciences, Dr. H. S. Gour Central University, Sagar 470003 , India (e-mail: pkm_8bh@yahoo.co.uk). 


\section{INTRODUCTION}

According to World Health Organization, out of the 102 major diseases, environmental risk factors contribute to disease burden in 85 categories. An estimated $24 \%$ of the global disease burden and $23 \%$ of all deaths (premature mortality) are attributable to environmental factors [1]. This represents a significant contribution to the overall disease burden, yet believed to be a conservative estimate as there is little understanding of any established doseexposure and exposure-response relationship analysis in environmental associated human ailments, including cancer. It is now believed that cancer has both a genetic and epigenetic component. The greater concordance of cancer incidence in twins and in families, studying cancer rates in migrant populations and cancer incidences by geography and over time exhibits an intimate gene-environmental relationship with disease aetiology [2].

A preponderance of evidence from multiple large prospective studies indicates that exposure to a wide array of natural and man-made substances in the environment accounts for at least $2 / 3$ of overall cancer burden [3]. Mode of action of the environmental toxicant at sub-cellular or molecular level is a fundamental obligatory step in induction of cancer. It is undeniable that direct toxic insults to DNA can have a profound impact on down-stream cellular effects leading to oncogenesis, however, array of epigenetic mechanisms might as well favor carcinogenesis [4]. Overall, the path from toxico-genomic insult resulting from environmental exposures to onset of a cancer phenotype involves multiple interacting molecular signaling pathways. It has now begun to be appreciated that individual genetic susceptibility, lifestyle, timing of exposure, and threshold level of exposure to environmental toxins might as well play a defining role in initiation and promotion of the disease $[5,6]$.

Arguably, the variability in cancer incidences may result from gene-environmental regulation at early life (prenatal, early childhood) or later (adolescence) exposures to environmental mutagens [1]. Malignant neoplasm at several sites of the body has been associated to specific kinds of cancer and exposures. For example, exposure to benzidine, a chemical found in certain dyes, is linked to bladder cancer [7], whereas exposure to asbestos is linked primarily to lung cancer [8]. In contrast, smoking is linked to cancers at multiple sites including lung, bladder, mouth, colon, kidney, throat, larynx, esophagus, lip, stomach, cervix, liver, and pancreas [2,3,5]. Exposure to environmental carcinogens is only a part of what determines who will get cancer. For example, some people who smoke do not get lung cancer, and not all women who are infected with human papilloma virus develop cervical cancer.

In post-genomics era, it has been increasingly realized that individual's genetic make-up or susceptibility plays a pivotal role in origin, development and dissemination of the cancer phenotype [9]. The probability that an individual will develop cancer in response to a particular acute toxic exposure depends on several interacting factors - quantum of exposure, period or duration of exposure, age, gender and health status [10]. Apart from these factors exposure to other environmental agents, diet, and individual lifestyle in due course of life also accounts for a major role. Following acute exposure to an environmental toxin, development of a tumor might take many years and even more years until it is detected. People exposed to carcinogens from smoking cigarettes, for example, generally do not develop detectable cancer for 20-30 years. As environmental exposures add to much more than genetic aspect towards onset and development of the disease, understanding the interplay between exposure risks and susceptible populations is critical to draw logical inference from dose-exposure relationship studies [5,6,11]. A high-quality epidemiologic investigation that evaluates exposure-response relationship is a crucial component in assessment of causes of cancer. However, quantitative exposure assessment in prototype culture model systems also has immensely contributed to our understanding of environmentally associated cancer risk. Exposure to environmental toxic agents is broadly divided into chronic 
or acute. While chronic involves repeated or continuous exposures over long periods, acute generally refer to single and higher dose of toxin exposure [12]. Despite the significant biological association of carcinogenic risks attributable to acute exposures, there exists many missing links and mechanistic details that have not been adequately addressed. An acute exposure may be encountered through food intoxication or through accidental industrial disasters releasing contaminants from industries or from any other sources. Most well known incidents of acute/short term exposure include: Seveso disaster of Italy; Belgian crisis of dioxin exposure; and Bhopal gas tragedy of methyl isocyanate (MIC) exposure $[13,14]$. Even though acute exposures (single dose, high concentration exposures over short periods) can prove to be detrimental, it is effects of chronic exposures (occupational carcinogens) that have been particularly well documented.

\section{METHYL ISOCYANATE}

Isocyanates and their derivatives have potential to cause toxic genomic effects $[6,15]$. The cyanate ion is an anion which consist of 1 oxygen atom, 1 carbon atom, and 1 nitrogen atom -[OCN]-. The group of low molecular weight aromatic and aliphatic compounds containing the isocyanate group [-NCO], are important raw materials with diverse industrial applications. Upon exposure, they bind to human tissues, proteins and DNA, forming toxic adducts and metabolites which may cause adverse health effect [16]. Methyl isocyanate (MIC), a reactive industrial byproduct, is one of the most toxic isocyanates known. This is an organic compound with the molecular formula $\mathrm{C}_{2} \mathrm{H}_{3} \mathrm{NO}$, arranged as $\mathrm{H}_{3} \mathrm{C}-\mathrm{N}=\mathrm{C}=\mathrm{O}$ (synonyms: isocyanate methane, methyl carbylamine), and was discovered in 1888 as an ester of isocyanic acid. MIC is a widely used chemical employed as a captive intermediate in the sealed production processes of polyurethane foams, insecticides such as aldicarb, carbaryl, carbofuran and methomyl, and plastic industries. It is usually handled and transported as a liquid, which is highly inflammable, volatile and has a strong odor. Cigarettes and tobacco smoke also contain MIC ( 4 $\mu$ g per cigarette). Methyl isocyanate is 1.4 times heavier than air and condenses in low-lying areas. Because of its high reactivity, MIC is used as an intermediate in organic synthesis, most notably in the production of carbamate pesticides and also in the production of rubber and adhesive. The MIC is prepared industrially by reacting methylamine with phosgene, oxidizing monomethylformamide at high temperatures $\left(>550^{\circ} \mathrm{C}\right)$, or heating metal MIC. Methyl isocyanate is considered to have poor warning properties because the human threshold for the detection of odor ( $>2 \mathrm{ppm}$ ) and mucous membrane irritation ( $>0.4 \mathrm{ppm}$ ) are higher than the $0.02 \mathrm{ppm}$ admissible threshold limit value [17,18]. Due to its nature and primary properties, MIC is known to exert detrimental effects on human health. Exposure to MIC during the Bhopal gas tragedy resulted in massive human carnage which is still quoted as an unflinching best example for acute exposure-related catastrophes in the history of environmental disasters $[5,6]$. The incident appraised the modern world about the enormity of toxic implications that can accidentally emerge from acute short term environmental chemical exposure.

Nearly 3 decades have elapsed since the incident took place (2 December 1984) and still there are half a million registered survivors of the tragedy ailing from various debilitating, life threatening illnesses (Table 1 and 2) [5,6]. Although it is most unfortunate that the accident has occurred, this has opened up an immense opportunity to learn about adverse effects of MIC and other such acute toxic exposures. In fact, the surviving cohort of this tragedy could possibly provide an unparallel opportunity to comprehend the long-standing implications of acute environmental toxic exposures and carcinogenic risk assessment. For a developing economy like India which is fraught with human, environmental and economical perils, dissecting out the effects of the Bhopal disaster employing a pragmatic and translational approach for cancer risk assessment will be of immense value and significance in dealing with future environmental hazards, if any (Figure 1). 
Table 1. Clinical symptoms observed during acute and subacute phases (1-6 months) after methyl isocyanate exposure

\begin{tabular}{|c|c|}
\hline Systemic sites affected & Symptoms diagnosed clinically \\
\hline General & $\begin{array}{l}\text { nausea, vomiting, fever, tingling, numbness, muscular weakness, sleep disorders like narcolepsy } \\
\text { or hypersomnia }\end{array}$ \\
\hline Respiratory & $\begin{array}{l}\text { distress, excessive productive (wet) and non-productive (dry) cough, shortness of breath, pulmonary } \\
\text { edema (abnormal build up of fluid in lungs), pain at the chest with uneasiness, bronchopneumonia }\end{array}$ \\
\hline $\begin{array}{l}\text { Psychological and } \\
\text { neurological }\end{array}$ & $\begin{array}{l}\text { anxiety, impaired auditory and visual memory, neurotic depression, declined attention response speed } \\
\text { and vigilance, social adjustment problem }\end{array}$ \\
\hline Gastrointestinal tract & abdominal pain, unremitting diarrhea, anorexia, loss of appetite \\
\hline Immunological & compromised cell mediated immunity, decreased T cell count, impairment in leucocyte phagocyting ability \\
\hline Genetic & elevated structural chromosomal anomalies \\
\hline Ophthalmic & $\begin{array}{l}\text { acute itchiness and burning sensation of eyes, abnormal sensitivity to or intolerance of light, obscured } \\
\text { vision, ulcerative keratitis, conjuctival and circumcorneal injection, acute glaucoma }\end{array}$ \\
\hline Reproductive & $\begin{array}{l}\text { spontaneous abortions, higher perinatal neonatal (death of a fetus or neonate in } 1 \text { st week of birth) } \\
\text { mortality, higher early neonatal (death of a live-born baby within 0-7 days) mortality, higher late neonatal } \\
\text { (death within 7-28 days) mortality, menstrual irregularities, high proportion of leucorrhoea, cervical } \\
\text { erosion, excessive menstrual bleedings, reduced lactation patterns in post-partum period }\end{array}$ \\
\hline
\end{tabular}

Table 2. Persistence of clinical symptoms in surviving population of Bhopal gas tragedy after 6 months (during chronic phase) of methyl isocyanate exposure

\begin{tabular}{|c|c|}
\hline Systemic sites affected & Symptoms diagnosed clinically \\
\hline Growth at adolescence & retarded growth and development in adolescent males exposed to MIC \\
\hline Respiratory & $\begin{array}{l}\text { excessive discomfort in chest with pain, dyspnea (uncomfortable breath), breath with exertion, wheezing, } \\
\text { diminished lungs functioning, bronchiectasis and stiffness in the lungs with restrictive expansion, } \\
\text { acute extrinsic allergic inflammation of the bronchioles leading to bronchopneumonia }\end{array}$ \\
\hline Ophthalmic & $\begin{array}{l}\text { complications in posterior ocular chamber affecting intraocular lens, corneal blurriness affecting vision, } \\
\text { infectious conjunctivitis (pink eye), chronic ocular abrasion, tear deficiency }\end{array}$ \\
\hline Immunological & $\begin{array}{l}\text { hyper-activated immune response in victims in utero exposed, increased levels of all circulating biomarkers, } \\
\text { higher prevalence of occult HBV/HCV and latent tuberculosis in affected individuals resulting from } \\
\text { immune alterations, significant incidences of HCV genotype-3 and gastro-intestinal tuberculosis cases } \\
\text { amongst gas victims }\end{array}$ \\
\hline Reproductive & $\begin{array}{l}\text { heightened loss of pregnancy rate, declined placental/fetal weight, leucorrhoea and dysmenorrhoea, } \\
\text { excessive vaginal discharge without previous history, profuse menstruations, premature menopause, } \\
\text { increased infant mortality }\end{array}$ \\
\hline $\begin{array}{l}\text { Psychological and } \\
\text { neurological }\end{array}$ & $\begin{array}{l}\text { defective cognitive ability with diminished standard progressive matrices and associated learning, reduced } \\
\text { motor speed, intellectual impairment, higher percentage of epileptics, frequent muscular aches in affected } \\
\text { population }\end{array}$ \\
\hline Cancer & $\begin{array}{l}\text { decrease in survival rate with increasing clinical extent of disease among survivors; rise of oro-pharyngeal } \\
\text { cancers; ascendance of gall bladder cancers (CaGB) with altered expressions of K-ras, p53, cyclin-E } \\
\text { and Rad50 proteins in exposed cohort; mixed chimerism of short tandem repeat (STR) loci in CaGB; } \\
\text { Population-Based Cancer Registry of India recorded maximum rise in cancer patterns in Bhopal } \\
\text { with } 96.4 \% \text { incidences recorded in men and } 102 \% \text { in women }\end{array}$ \\
\hline
\end{tabular}

MIC - methyl isocyanate; HBV - hepatitis B virus; HCV - hepatitis C virus; CaGB - carcinoma of gall bladder; STR - short tandem repeat. 


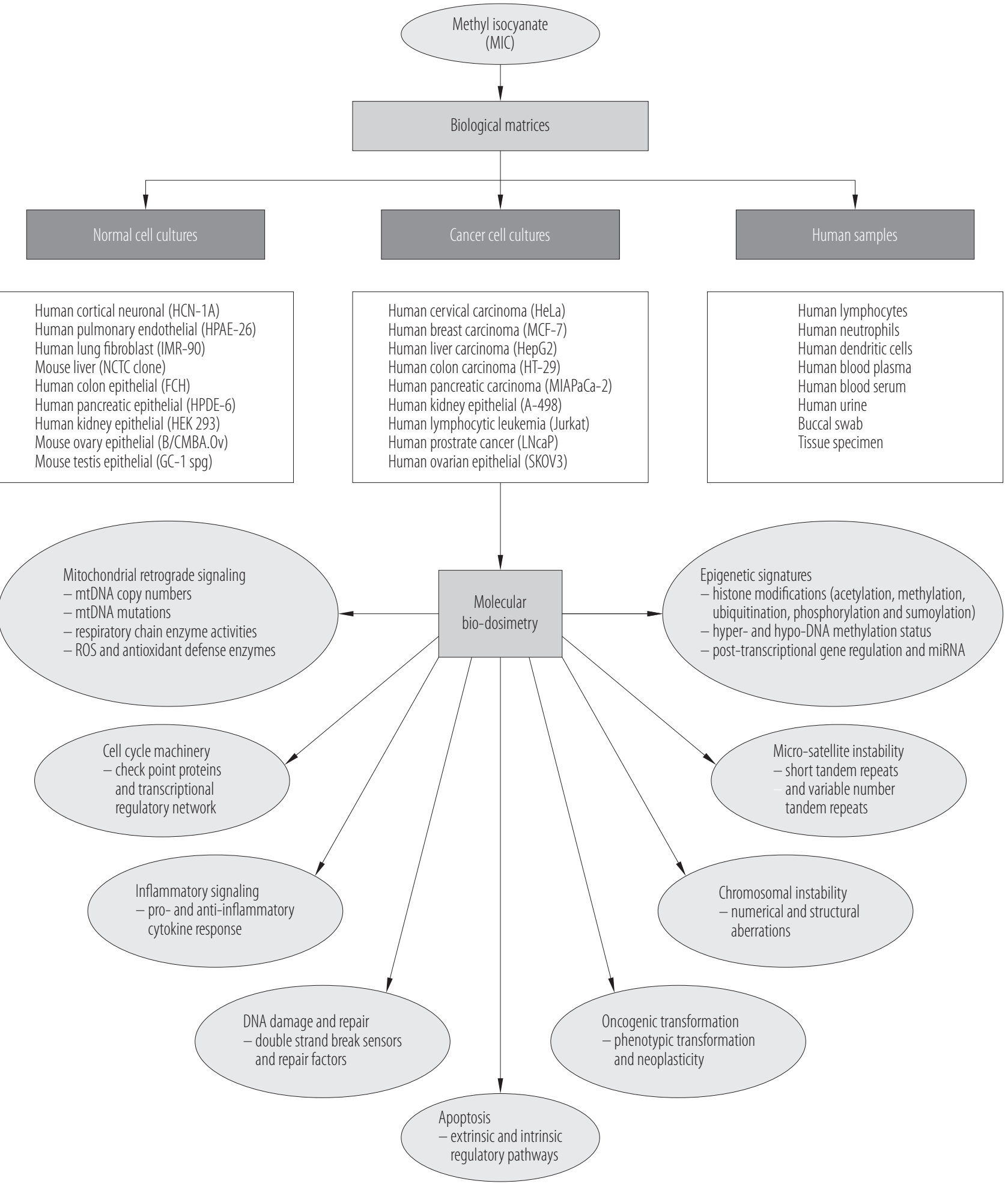

mtDNA - mitochondrial DNA; ROS - reactive oxygen species; miRNA - micro-RNA.

Fig. 1. A pragmatic molecular bio-dosimetry strategy for evaluation of cancer risk among survivors of the Bhopal gas tragedy 


\section{DOSE-EXPOSURE}

\section{AND EXPOSURE-RESPONSE RELATIONSHIPS}

The Indian Council of Medical Research (ICMR) was one of the foremost organizations to initiate clinical research studies on the affected population. As part of the ICMR investigations, 24 research projects were carried out in between 1985 to 1994 on 80000 persons at severely, moderately and mildly exposed areas and compared with controls from unexposed areas. The findings were presented in form of a technical report "Health effects of the toxic gas leak from Union Carbide methyl isocyanate plant in Bhopal" [19]. However, the global scientific community considered the exposure and toxicity assessment incomplete. Similar thoughts were also voiced by international groups who advocated long-term investigations on the toxico-genomic effects of MIC using cutting edge technologies [20]. The importance of such statements could not be undermined, as any alteration at genomic and/or epigenetic level during the acute toxic exposure can potentially result in long term health repercussions including accelerated ageing, carcinogenesis, immuno-compromised states and, more importantly, vertical transmission of genetic aberrations.

With the sole objective to examine long-term health effects of MIC in the surviving population of the Bhopal gas tragedy, Research Wing of Bhopal Memorial Hospital and Research Centre (presently under ICMR) was established in 2004. Through well designed and multi-disciplinary scientifically validated efforts (spanning close to a decade now), author and his team delineated toxico-genomic potential of MIC at genome, proteome and cytome level. Inflammatory signaling, interference in mitochondrialnuclear cross talk, DNA damage repair response evaluation, regulation of cell cycle machinery, numeric and structural chromosomal aberrations, microsatellite instability, heritable transgenerational traits, stress-induced premature senescence, epigenomic signatures, oncomarkers and immune status of exposed and dependents (generation born after the mishap) were comprehensively evaluated using in vitro model systems and in clinical samples of MIC-affected population. The issues were addressed by devising unique approaches involving specific fingerprints for defined mechanisms that exhibit dose-exposure and exposure-response relationships (Figure 1).

\section{Chronic inflammation}

Aberrant inflammatory signaling plays a crucial role in the induction of cellular proliferation and extends the prolonged cell survival through activation of oncogenes/inactivation of tumor-suppressor genes resulting in genetic instability with an increased risk of carcinogenesis. The 2 phenomena are associated with each other on one hand through an extrinsic mechanism, wherein a constant inflammatory state contributes to increased cancer risk; on the other hand, by an intrinsic mechanism involving acquired genetic alterations-mediated tumor development. Whereas the former increases the risk of cancer development, the latter promotes cancer progression [21]. Precisely, roles and relationship between the 2 pathways in the tumor development depend on their specific interactions between genetic and epigenetic factors and environmental factors.

Acute or chronic exposures to chemicals and infectious agents are known to create an inflammatory microenvironment that facilitates initiation of carcinogenesis $[22,23]$. In this context, the pro-inflammatory cytokine response in human lymphocytes and neutrophils; human lung fibroblasts (IMR-90), human colon epithelial (FHC) cells treated with $0.005 \mu \mathrm{M}(1 \mu \mathrm{g} / \mu \mathrm{l}) \mathrm{MIC}$ were evaluated. Flow cytometric analysis revealed a time- and dose-dependent escalation in the levels of the inflammatory cytokines interleukin 6 (IL-6), tumor necrosis factor $\alpha$ (TNF- $\alpha$ ), interferon gamma (IFN- $\gamma)$, IL-8, IL-1 $\beta$, nuclear transcriptional factor $\kappa \beta$ (NF-к $\beta$ ) and IL-12p70 in culture supernatants of cells studied [24-27].

A parallel study performed in a strictly selected surviving cohort of the Bhopal gas tragedy not only manifested 
significant enhanced levels of circulating inflammatory mediators, but presented a persistent and subtle toxic effect that well corroborated with the results of in vitro experiments [28]. Therefore, well designed genome-wide association studies in a restricted cohort might help to understand the precise role of inflammatory-mediated cancer risk and also identification of a suitable biomarker for wide-spectrum population screening.

\section{Mitochondrial retrograde signaling}

Mitochondrial oxidative stress is one of the putative mechanisms of a pro-inflammatory cytokine response. During inflammasome-independent pro-inflammatory cytokine production, mitochondrial reactive oxygen species (mtROS) modulate the equilibrium between positive and negative regulators, which results in an increase in the rate of transcription of cytokines [29].

The mitochondrion plays a pivotal role in cellular homeostasis not only by generating the vast majority of the supply of adenosine triphosphate (ATP), but also by influencing apoptosis, cell cycle, and metabolism [30]. Through aerobic respiration, mitochondria generate ATP that oxidize glucose, pyruvate, and nicotinamide adenine dinucleotide and hydrogen (NADH), and contribute to the formation of reactive oxygen species (ROS) as a byproduct [31]. Under normal physiological circumstances, the deleterious effects caused by the highly reactive nature of ROS are balanced by the presence of antioxidants, including glutathione, carotenoids, and antioxidant enzymes such as superoxide dismutase, glutathione reductase, catalase and glutathione peroxidase [32]. However, hyper-generated levels of ROS overwhelm the endogenous antioxidant defenses of the host cell, which in turn favors the production of excessive free radicals and thus emanation of oxidative stress [33]. Free radicals thus generated impact biochemical component of the cell, with lipids, proteins and nucleic acids being the most important targets.
We evaluated this plausible role of MIC exposure in our experiments using HEK-293 (human embryonic kidney epithelial), GC-1 spg (mouse spermatogonial) cells and HPAE-26 (human pulmonary arterial endothelial) cells. The production of intracellular ROS was measured in terms of hydrogen peroxide $\left(\mathrm{H}_{2} \mathrm{O}_{2}\right)$ production by dichlorofluorescin (DCFH) oxidation. An early and continual increase in the ROS generation was recorded in the treated GC-1 spg, HEK-293 and HPAE-26 cells [34-36]. These observations imply that excessive accumulation of $\mathrm{H}_{2} \mathrm{O}_{2}$ in $\mathrm{MIC}$ exposed cells could lead to pronounced oxidative damage and instigate a variety of cellular responses including inflammasome activation. The up-regulation of pro-apoptotic BAX gene along with increased activation of annexin $\mathrm{V}$ and caspase-3 proteins in human lymphocytes, neutrophils, GC-1 spg, MM55.K, IMR-90 and FHC cells depicted considerable amount of apoptosis due to MIC treatment along time course [24-27,34,35].

\section{Oxidative damage}

With over a hundred oxidative DNA adducts, oxidative DNA damage is also a major source for the mutation load in living organisms. By virtue of the highly reactive nature, the hydroxyl radical, generated from $\mathrm{H}_{2} \mathrm{O}_{2}$, is the predominant ROS that targets DNA by forming oxidized bases [37]. The best biomarkers for oxidative damage include the 8-oxo-dG, a modified nucleoside base detected as a byproduct of DNA damage repair and apurinic sites with open ring form on the damaged DNA detected by aldehyde reactive probe (ARP) reagent that reacts specifically with an aldehyde group [38-40]. On the other hand, antioxidant defense enzyme systems such as superoxide dismutase (SOD) and glutathione reductase (GR) act as the 1st line of defense against the toxicity of ROS (superoxide radicals) resulting from oxidative damage and any depletion in the activities of these enzymes against chemical damage can result in oxidative turbulence in 
cellular homeostasis with the breakdown of antioxidant protection system [41].

Correspondingly, our investigations in MIC treated HEK-293, GC-1 spg and HPAE-26 cells revealed significant induction of oxidative stress through accumulation of 8-oxo-dG bases and ARP sites in the DNA and inhibition of both SOD and GR activities [34-36]. These results suggest that MIC provokes cells to be more vulnerable to free radical-induced oxidative damage, increased protein thiolation or oxidation of thiol groups and indirectly contributes to the ineffective repair of DNA damage and acquisition of the damaged genotype.

\section{DNA double strand breaks}

Toxic oxygen metabolites such as hydroxyl radical can covalently attack nucleophilic sites of nucleic acids causing base hydroxylation, cross-linking or scission of DNA strands and wreak havoc in cells by causing single- or double-strand DNA breakage which could lead to mutagenic effects [42]. Due to their electron loving chemistry, isocyanates have been known to react with exocyclic amino group of deoxynucleotides (dNTP's) to yield carbamoylated DNA cross links/adducts and thus attribute to the biotransformation reactions [43,44]. Double-strand breaks (DSB) resulting from interstrand crosslinks/adducts are the most deleterious form of DNA damage and appropriate cellular signaling of DNA damage response is imperative for efficient resolution of the damage. This network includes an ataxia telangiectasia mutated (ATM) protein kinase cascade that connects the detection of DNA damage to the activation of a vast array of downstream checkpoint, transcriptional and regulatory pathways [45].

In this regard, cellular response to MIC induced DSB and factors affecting genomic stability were investigated through measurement of phospho-serine protein kinases ATM, ATR and H2AX expression through immunolabeling. Qualitative immunofluorescence microscopy in mouse B/CMBA.Ov (ovarian epithelial), MM55.K (kidney epithelial), GC-1spg (spermatogonial) and NCTC-1469 (liver epithelial) cells along with human IMR-90 (lung fibroblast) and FHC (colonic epithelial) cells after treatment with MIC showed elevated expression of pATM, g-H2AX and p-p53 proteins with interspersed and punctuated nuclear pattern. On the other hand, quantitative analysis through flow cytometry in GC-1 spg, IMR-90 and FHC cells displayed an analogous upshot in phosphorylation time kinetics of expression of $\mathrm{p}-\mathrm{ATM} / \gamma-\mathrm{H} 2 \mathrm{AX}$ and p-p53 proteins [25,26,34,35,44,46,47]. Our results imply that MIC treatment causes the formation of carcinogen-DNA adducts and induces alterations to DNA ultra-structure.

\section{DNA repair response}

Double-strand breaks are potentially lethal, and cells have evolved a mechanism leading to recruitment of repair proteins. Despite the presence of highly conserved various mechanistic modes to detect and repair lethal DNA damage, in cells confronted with excessive genotoxic stress stimuli, these mechanisms are not always effective enough, leading to accumulation/replication of lesions. Deregulated DNA damage repair, especially due to DNA breaks/cross links, has been suggested to be catastrophic to the integrity of the genome.

Analysis of damage repair factors Mre11, Rad50 and Nbs1 in our studies with MIC treated B/CMBA.Ov and NCTC1469 cells revealed abrupt augmentation in their expression pattern, suggesting the active recruitment of these proteins in response to severity of stress-induced DNA damage and cycle arrest due to active accumulation and trans-activation of check-point genes [46,47]. The family of growth arrest and DNA damage (GADD) nuclear proteins (GADD45 $\alpha$ in particular) delays the cell cycle progression whenever there is genotoxic stress and is specifically involved in the nucleotide excision repair mechanism of DNA and regulates the cellular survival. However, the observed altered expression of GADD45 $\alpha$ protein in MIC exposed B/CMBA.Ov 
cells indicated compromised state of genome and increased susceptibility to carcinogenesis $[46,47]$.

\section{Cell cycle deregulation}

In addition, excessive accumulation of DNA damage responsive factors causes early cell cycle arrest. Cell-cycle arrest occurs in response to cellular stress through activation of regulatory checkpoints. Increased p53 activity in response to DNA damage blocks the proliferation of cells in the G1 phase of the cell cycle [48]. In line with this cellular phenomenon, authors' findings in IMR-90, FHC and B/CMBA.Ov cells treated with MIC showed significant cell cycle arrest both at early G1 and G2/M phases, eventually setting the stage for aneuploidy [25,26,47]. These results indicate imbalance in ploidy levels and are probably the response of check-point proteins and interruption of cell cycle progression, due to toxic MIC treatment.

\section{Cell cycle checkpoints}

In mammalian cells, checkpoint systems represent complex networks that integrate the machinery of cell cycle with DNA repair pathways and lifespan control. For DSB resection, several kinases are coordinately activated which are simultaneously regulated positively by cyclins and cyclin-dependent kinases (CDK) and negatively by CDK inhibitors [49].

Upon examining the role of cell cycle regulatory proteins after MIC treatment in HEK-293, B/CMBA.Ov and NCTC-1469 cells, the authors noted an abrupt upregulation in the levels of both tumor suppressor p53 and cyclin dependent kinase inhibitor $\mathrm{p} 21^{\mathrm{WAF} / \mathrm{Cip} 1}$ proteins. Incidentally, the early G1 phase arrest of cell cycle observed after MIC exposure further corroborated with the marked increase in expression of these proteins. In addition, a temporal upshot of $\mathrm{p} 16^{\mathrm{INK} 4 \mathrm{~A}}$ and sequential up-regulation of $\mathrm{pRb}$ proteins along with downregulated expression of cyclin D1 in MIC exposed cells alluded to the deregulated cell cycle with significant impediment in G1/S transition phase caused by MIC exposure [26,46,47]. Furthermore, the transitions between late G1, and G1-S and $\mathrm{G} 2 / \mathrm{M}$ cell cycle phases are regulated by cyclins $\mathrm{A} / \mathrm{E}$ in conjunction with their catalytic partners CDK2 through their nuclear translocation to control cell cycle progression, DNA synthesis and mitosis [50]. Interestingly, in our studies with NCTC-1469, GC-1 spg and HEK-293 cells we observed an uncontrolled activation/overexpression of cyclin A, cyclin $\mathrm{E}$ and $\mathrm{CDK} 2$ proteins at different passages 1 to 5 post MIC treatment suggestive of deregulated G1/S transition machinery with sub-optimal S phase allowing mitotic slippage and initiation of genomic instability $[26,46,47]$.

\section{Genomic instability}

In every population of cells, besides the continuously proliferating cycling cells and terminally differentiated cells that are destined to die, there exists a 3rd kind of subpopulation of cells which, though non-dividing, can re-enter the cell cycle upon acquiring an appropriate growth factor or other stress stimulus. Defective intra-cellular pathways of cell cycle and differentiation and/or signaling molecules might underlie the undeterred growth and genetically unstable phenotype [51-53]. Chemical agents, in this regard, can induce genetic alterations in susceptible cells imparting a selective growth advantage by deregulation of checkpoint signaling protein kinases, providing opportunity to cells for clonal expansion by aberrant mitosis leading to genomic instability [54]. Aurora kinases represent a novel family of serine/threonine kinases regulating crucial mitotic segregation. Deregulation in aurora kinases A and B has been linked to tumorigenesis.

In our experiments with NCTC-1469 and GC-1spg cells in response to MIC exposure, we examined the functioning of these 2 crucial mitotic kinases. While reverse transcriptase PCR analysis of aurora kinase1 gene showed an aberrant amplification at passage 1 and 2, immunocytochemical analysis revealed overexpression of aurora 
kinase B protein at passage 2 in the treated cells indicative of mitotic slippage by override of the checkpoint arrest through rapid exit from mitosis and defective spindle assembly checkpoint and aneuploidy resulting in genomic instability [35,46].

Deregulated aurora kinase activities can impact organization of the cytoskeleton and result in defective centrosome function sustained G1 arrest along with persistent cyclin E overexpression and eventually mitotic abnormality [55]. Our investigations in MIC treated IMR-90, HEK-293 and FHC cells presented the overexpression of centrosomal protein pericentrin levels suggestive of an abnormal centrosome functioning, thereby generating supernumerary centrioles and improper segregation of chromosomes during cell division. Moreover, surpassing of the cellular capacity to aptly manage spindle assembly checkpoints results in chromosome mis-segregation with subsequent "gain of chromosomal-instable phenotype" and leads to profound karyotype instability [56]. Environmental mutagenic agents, in this regard, can predispose and produce heritable chromosomal aberrations leading to unbalanced complements of chromosomes with varying degrees of severity. Such structural chromosomal rearrangements and losses/gains from non-disjunctions and multipolar mitoses are perceived to be the major factors for aneuploidy [57]. In our published studies, the ability of MIC to induce chromosomal instability was evident from the results obtained with cytogenetic analysis of treated B/CMBA.Ov, NCTC1469, GC-1 spg, HEK-293, IMR-90 and FHC cells. Metaphase spreads obtained from treated cells showed an array of structural chromosomal aberrations in the form of chromatid fragmentation, p-p arm Robertsonian fusions, premature centromeric separation, dicentrics, chromatid breaks, ring, end-to end fusion, endo-reduplication, markers, double minutes, tri- or quadric-radials. Simultaneously, evaluation of the numerical cytogenetic index revealed a significant percent gain and loss of whole chromosomal number indicating propensity towards aneuploidy and polyploidization of chromosomes in treated cells at passage level. These results summed up the occurrence of chromosomal instability induced after MIC exposure. The incidence of these aberrations was further confirmed by molecular cytogenetic studies involving centromeric FISH and telomeric FISH. Centromeric FISH unraveled the centromeric amplification of $\alpha$-satellite repeats in MIC treated HEK-293 and NCTC-1469 cells, suggesting that this portion of the genome may be destabilized and might lead to "neo-centromerization;" whilst telomeric FISH in MIC exposed B/CMBA.Ov, GC-1 spg and NCTC-1469 cells further confirmed the incidence of p-p arm Robertsonian fusions by demonstrating the loss of telomeric repeats (absence of signals at telomeric sites) of chromosomes. This loss of telomeric integrity was further validated by immune-FISH showing depleted expression of telomeric proteins TRF-2 and Pot1a in treated cells signifying their vital role in mammalian telomere end protection and regulation of telomere length [25-27,35,46,47]. Intriguingly, exposure to toxic chemicals also causes subtle lesions in telomeric regions which, if undetected, could destabilize the chromatin bridges in proliferative cells and therefore compromise the stability of genome. Concurrently, our spectral karyotype (SKY) analysis in MIC treated HEK-293 and NCTC cells, respectively, showed incidence of cryptic and multiple translocations implying the greater susceptibility of telomeres to isocyanate exposure, which, consecutively, might play a part in transfer of instability from one chromosome to another through abnormal telomeres and generate many types of rearrangements $[34,46]$. Collectively, our investigations have confirmed that there is a synergistic inception of chromosomal instability in the genome as indicated by various unstable-type chromosome aberrations.

Moreover, it is rationalized that the persistence of DNA strand breaks/damage during DNA cycling can cause unwanted slipped strand mis-pairing (slippage) and increased rate of mutation/variation in microsatellite 
repeats in comparison to other neutral regions of DNA in mammals [58]. In this regard, inter simple sequence repeat (ISSR) PCR analysis in MIC treated IMR90, FHC, GC-1 spg and NCTC-1469 cells, presented the variable amplification or distribution pattern of ISSR $(\mathrm{CA})_{8}$ repeats in the form of gains, losses, or intensity changes in the number of bands indicating the extension of genetic instability to microsatellites $[25,26,35,46,47]$. We postulate that the variable amplification of bands in ISSR fingerprint profile might result (because of potential alteration in DNA secondary structure by MIC) in extension of minor groove width that increases the accessibility and reactivity of individual hydrogen atoms of ribose moieties with MIC, thus giving credence as the end point of genomic instability.

\section{Oncogenic transformation}

Genomic instability plays a major part in the cellular drift towards phenotypic transformation. Progressive and persistent DNA damage in live cells by oxidants is the key factor contributing to cell ageing and preconditioning to phenotypic transformation. Redox-cycling of xenobiotic compounds and the entry of cells into senescence triggered by oncogene overexpression, in part mediated by oxidative stress, may collectively contribute to undesirable inadvertent cellular transformation [59]. Experiments performed in HEK-293 and GC-1 spg cells exposed to MIC further substantiate these observations by means of the morphological variations and increased uptake of $\beta$-gal stain by these, probably transformed, senescent cells manifested at higher time course and passage levels [34,35].

\section{Stress-induced premature senescence}

On the contrary, induction of a stress induced senescencelike phenotype occurs after environmental and genotoxic insults and several treatments can stimulate and accelerate a senescence-like state prematurely in young cells. This forces cells to acquire multiple phenotypic changes, thereby compromising the tissue architecture and function [60]. Consistent with this, our investigation in B/CMBA.Ov cells showed an increase in the cell size, a characteristic feature of senescence with early induction of positive staining for $\beta$-galactosidase in MIC exposed cells in-advance with large granular nucleus and focal enrichment of lysosome-related $\beta$-galactosidase activity at vacuoles which persisted progressively along the incremental time course [47]. These outcomes further support the notion that an increase in lysosomal mass is responsible for the increase in $\beta$-galactosidase activity observed in senescent cells.

\section{Neoplasticity}

In some cells, senescence-associated DNA damages due to mutagenic exposure could affect a cocktail of oncogenes and tumor-suppressor genes, favoring an evolution toward transformation or immortalization. In order for transformed cells to be generated from senescent cells, there must be some mutagenic events that occur during senescence. The importance of a high rate of mutations associated with senescence in the development of tumors is associated with numerous DNA alterations and mutations and increased cancer incidence [61]. Consistent with this, MIC treated B/CMBA.Ov cells exhibited morphological variations with emergence of daughter clones from senescent mother phenotypes. In vitro cellular transformation assay after 8 days of culture presented striking appearance of anchorage independent growth in clusters having refractile property suggesting that cells, already partially transformed, are highly prone to further neoplastic development upon exposure to isocyanates [47].

\section{Epigenetic signatures}

Chromatin changes are intimately linked with DNA damage response. Overaccumulation of defectively repaired adducts due to impaired mitochondrial-nuclear cross talk alters epigenetic programming through introduction 
of negative charge on the chromatin structure $[62,63]$. Of late, reports have revealed redox signaling as a vital determinant for epigenetic programming that might have significant impact on post translational modifications. Various epigenetic marks including DNA methylation and histone modifications viz. methylation, acetylation, ubiquitination and phosphorylation have been directly related to crucial redox intermediates such as $\mathrm{NAD}+, 8-\mathrm{OHdG}$, S-adenosyl methionine. Normal and pathologic stimuli originating from fluctuations of these intermediates might disturb epigenetic modifications, leading to a cascade of aberrant gene expression sequel. Intracellular signals that prompt from oxidatively damaged fragile sites might influence transcriptional changes including several miRNA-producing transcripts. Albeit miRNA expression is controlled by transcriptional machinery, there is increasing evidence that protein regulators of the miRNA expression can also be affected during genomic instability [64] that is insinuated following pro-oxidant exposures such as MIC. Destabilization of epigenetic signature due to oxidative modifications might also influence telomeric function as guanine rich nucleobases at telomeres are highly susceptible to oxidative changes [65]. Irreparable damage at telomeric sites might serve as a signal for senescent state, eventually perpetuating a self-cascade cycle of inflammatory associated secretome [66].

A recent study from our laboratory has shown that perturbation in mitochondrial machinery led to hypermethylation of p16 and smad4 gene promoters and downregulation of respective gene products following MIC exposure in human pancreatic epithelial cells. Post-translational histone modifications that include hypo-acetylation of $\mathrm{AcH} 3$ and $\mathrm{AcH} 4$, hypermethylation of $\mathrm{H} 3 \mathrm{~K} 9 \mathrm{me} 1$ and $\mathrm{H} 4 \mathrm{~K}$ 20me3, ubiquitinated $\mathrm{uH} 2 \mathrm{~A} / \mathrm{uH} 2 \mathrm{~B}$ and increased phosphorylation of $\mathrm{H} 2 \mathrm{AX}$ and $\mathrm{H} 3$ were observed in the isocyanate treated cells. Altered expression of miRNAs denoted possible location of corresponding genes at oxidatively damaged fragile sites [67]. Similarly, a direct role of mitochondrial oxidative stress induced aberrant chromatin regulation, as a central phenomenon, to perturbed genomic integrity in the ovarian and testicular milieu has also been recently reported $[68,69]$. From our studies it is quite evident that in vivo studies will be imperative to dissect the putative role of MIC-induced epigenetic modifications. Further, identification and characterization of molecular switches that affect these epigenomic signatures and targets thereof will be necessary to understand the complex role of MIC-driven aberrant chromatin response at a greater depth.

\section{Infection-driven cancers and epigenomic links}

Epigenetic studies have abruptly changed our vision of the determinants of exogenous influence on human ailments. Mechanistic laboratory investigations and clinicoepidemiological data have provided insights of heritability of epigenetic traits suggesting molecular influence of the environment to extend well beyond the interaction with the DNA sequence. A persistent hyper-responsive cellular and humoral immune state observed 2 decades later in individuals in utero exposed to MIC during the Bhopal gas tragedy offers a potential insight into epigenetic modulation of the immune system [70].

A retrospective surveillance for monitoring possible health effects for the hepatitis infections amongst the 1st and 2nd generations of survivors of Bhopal gas tragedy revealed hepatitis virus infections to be most common among the MIC exposed cohort [71-74]. Genotype 3 of hepatitis $\mathrm{C}$ virus (HCV) was the most prevalent $\mathrm{HCV}$ genotype among the survivors $[75,76]$. Failure to detect surface antigen of the hepatitis B virus (HBsAg), hepatitis B core antibody (anti-HBc) and anti-hepatitis $\mathrm{C}$ antibodies (anti-HCV) through enzyme-linked immunosorbent assay (ELISA) in significant number of samples indicated higher prevalence of occult hepatitis (HBV/HCV) in the MIC affected population [75]. As the risk of progress 
of infection is often influenced by condition and nature of chemical exposure, insights of interconnected pathways between aberrant epigenetic modification and manifestations of hepatitis-induced carcinogenesis might offer valuable information for shaping better strategies of prevention and management of these infectious trends in the MIC-exposed population. Implementing designer personalized therapeutic strategies such as dendritic cell based vaccines may be a promising strategy against such infection-associated cancers [77-80].

\section{A pragmatic model with clinical translation potential}

As 30 years have elapsed following the exposure to MIC in Bhopal, to establish a cohort of exposed individuals, inclusion criteria need to be carefully validated. Of course, it would require painstaking efforts to identify and ensure that the individuals were indeed exposed to MIC. Notwithstanding the concerns, ascertainment of MIC exposure must rely on the following criteria:

- physical presence and address of stay on the night of MIC leak from the factory,

- distance from the factory,

- protective measures taken at the time of gas leak, if any,

- remained outdoor or indoor,

- if outdoor, what was the activity profile, i.e., running or exertion or walking or driving, etc.,

- the overall symptom profile like respiratory, cutaneous and ocular symptoms on that night to corroborate exposure.

Besides, non-exposed healthy controls should be recruited from places within the geographical region of Bhopal but from unaffected zones (more than $25 \mathrm{~km}$ from the plant) and from places well outside geographical region of Bhopal (more than $200 \mathrm{~km}$ from the plant). Any confounding factor such as socio-economic conditions, history and duration of stay, tobacco use/alcohol consumption, and any significant medical history impeding the evaluatory framework of exposure-response relationship should be carefully monitored during subject recruitment. As required for any risk assessment studies, the investigative strategy will require:

- Suitable biological matrices - easily accessible in sufficient volumes under routine conditions. Samples should be collected and stored using standard operating procedures.

- Selection of parameters of the study should be able to reflect internal incidental exposure and biochemical effects.

- Quality control and assurance of the analytical methods employed should be validated for efficient interpretation of results.

Exponential increase in cancer cases world-wide has been often linked to perturbations in gene-environment interactions, therefore, molecular carcinogenic risk-assessment eloquently addresses gene-environment interaction and inter-individual variation through multidisciplinary efforts. This includes epidemiology, genetics, cell biology, immunology and statistics. Post-modernization, cancer risk evaluation is often attached great clinical importance but as occupational diseases continue to dominate global concerns, strategies have better evolved for evaluation of systemic uptake from chronic (long-term) in comparison to acute (short term and peak) environmental toxic exposures. Associated with modern life style, cancer risk from occupational exposure is a major cause of concern. Not ascribed enough importance, predisposition to carcinogenic risk following accidental exposure still remains an intricate issue that needs to be debated and discussed. In such a scenario, a pertinent question that emerges is whether acute short-term exposure (1 h to 10 days) to highly toxic substance/s could possibly contribute to long-standing repercussions and if so, whether these implications can be quantified employing definitive measures.

Exposure analysis that possibly augments cancer risk can be performed through molecular bio-dosimetry 
(i.e., measuring indices of mitochondrial oxidative stress, inflammatory cytokine response, DNA damage and repair response, apoptosis, genomic instability and epigenetic signatures), which reflects a biologically effective dose. Bhopal, as a model could provide an unparallel opportunity for risk assessment that would forecast an individual's susceptibility to carcinogenesis after an accidental (acute) environmental toxic exposure. Recognizing cancer as a multi-factorial disease, the proposed risk-assessment study will use bio-dosimetry of cancer risk that elucidates multiple gene-environment interactions, where several genetic and epigenetic signaling pathways indulge interactively. The 3 recognized facets of molecular surveillance of human cancer risk:

- inherited host susceptibility factors, which negatively or positively regulate the exposure to onset of a cancer phenotype,

- molecular bio-dosimetry of exposure indices that identifies the dose of exposure that altered macromolecules such as DNA and proteins during or post-exposure,

- biomarkers of patho-biologic effect still persisting must be given equal emphasis.

Besides genetic, subtle alterations such as DNA hyper/hypo-methylation with subsequent extent of histone modifications in the form of histone acetylation, deacetylation, ubiquitination and sumoylation might outline the epigenetic aspects of the MIC induced carcinogenesis. In addition, global gene expression and transcriptomic profiles might yield informative signatures for phenotype of a complex disease such as cancer and genotype, i.e., DNA polymorphisms.

During the last decade-long period, our systematic laboratory investigations coupled with molecular surveillance studies have comprehensively demonstrated that the risk of developing an environmental associated aberrant phenotype following MIC exposure involves complex interplay of genomic and epigenetic reprogramming. These findings poised us to translate this knowledge into an investigative framework of "molecular bio-dosimetry" in a strictly selected cohort of individuals exposed to MIC during the accident. It is now imperative to design a coherent strategy by initiating a debate involving experts and linking national and international institutions of repute working on environmental health risk assessments.

Given that mitochondrial retrograde signaling-induced epigenetic reprogramming is apparently linked to neoplasticity, a cutting-edge tailored approach will be fundamental to drive these strategies from bench to bedside. Validating the epigenomic signatures will hopefully result in the development of biomarkers to better protect human lives in an overburdened ecosystem which is continuously challenged to meet population demands. Lack of scientific ambience and academic amalgamation due to socio-demographic deficits has been a major impediment towards developing a committed inter-disciplinary talent pool of experts in Bhopal. Organizational restructuring, institutional impetus and infusion of necessary funds will help to build a team of bio-medical researchers with rich expertise to undertake the investigation and owe the ambitious responsibility. Although the challenges are enormous, we postulate that the study will be necessary to establish a direct initiation-promotion paradigm of environmental carcinogenesis. While it is most unfortunate that the accident occurred in Bhopal, this possibly offers a unique opportunity to learn the ramifications of acute toxic exposures. Besides providing preventive management of future industrial disasters and refining risks that mankind faces from chemicals and other environmental hazards, specific biomarkers that characterize personal exposure analysis might aid in shaping strategies to help the ailing survivors of the tragedy. From a translational oncologist's perspective, the investigations might also help to formulate suitable regulatory policies and measures to reduce the overall societal burden of environmental carcinogenesis. 


\section{REFERENCES}

1. Knol AB, Petersen AC, van der Sluijs JP, Lebret E. Dealing with uncertainties in environmental burden of disease assessment. Environ Health. 2009;28(8):21, http://dx.doi. org/10.1186/1476-069X-8-21.

2. Matakidou A, Eisen T, Houlston RS. Systematic review of the relationship between family history and lung cancer risk. Br J Cancer. 2005;93(7):825-33, http://dx.doi.org/10.1038/ sj.bjc.6602769.

3. Ferlay J, Shin HR, Bray F, Forman D, Mathers C, Parkin DM. Estimates of worldwide burden of cancer in 2008: GLOBOCAN 2008. Int J Cancer. 2010;127(12):2893-917, http:// dx.doi.org/10.1002/ijc.25516.

4. Severson PL, Tokar EJ, Vrba L, Waalkes MP, Futscher BW. Coordinate $\mathrm{H} 3 \mathrm{~K} 9$ and DNA methylation silencing of ZNFs in toxicant-induced malignant transformation. Epigenetics. 2013;8(10):1080-8, http://dx.doi.org/10.4161/ epi.25926.

5. Mishra PK, Samarth RM, Pathak N, Jain SK, Banerjee S, Maudar KK. Bhopal gas tragedy: Review of clinical and experimental findings after 25 years. Int J Occup Med Environ Health. 2009;22(3):193-202, http://dx.doi.org/10.2478/ v10001-009-0028-1.

6. Mishra PK. A pragmatic and translational approach of human biomonitoring to methyl isocyanate exposure in Bhopal. Indian J Med Res. 2012;135(4):479-84.

7. Letašiová S, Medvedová A, Šovčíková A, Dušinská M, Volkovová $\mathrm{K}$, Mosoiu C, et al. Bladder cancer, a review of the environmental risk factors. Environ Health. 2012;11 Suppl 1:S11, http://dx.doi.org/10.1186/1476-069X-11-S1-S11.

8. Stayner L, Welch LS, Lemen R. The worldwide pandemic of asbestos-related diseases. Ann Rev Public Health. 2013;34:205-16, http://dx.doi.org/10.1146/annurevpublhealth-031811-124704.

9. Pérez-Losada J, Castellanos-Martín A, Mao JH. Cancer evolution and individual susceptibility. Integr Biol (Camb). 2011;3(4):316-28, http://dx.doi.org/10.1039/c0ib00094a.
10. Chiu WA, Euling SY, Scott CS, Subramaniam RP. Approaches to advancing quantitative human health risk assessment of environmental chemicals in the post-genomic era. Toxicol Appl Pharmacol. 2013;271(3):309-23, http:// dx.doi.org/ 10.1016/j.taap.2010.03.019.

11. Mishra PK, Raghuram GV, Bhargava A, Pathak N. Translation research in molecular disease diagnosis: Bridging gap from laboratory to practice. J Glob Infect Dis. 2011;3(2): 205-6, http://dx.doi.org/10.4103/0974-777X.81705.

12. Rozman KK, Doull J, Hayes WJ Jr. Dose and time determining, and other factors influencing, toxicity. In: Krieger R, editor. Hayes' handbook of pesticide toxicology. 3rd ed. New York: Academic Press; 2010. p. 3-101, http://dx.doi. org/10.1016/B978-0-12-374367-1.00001-X.

13. Covaci A, Voorspoels S, Schepens P, Jorens P, Blust R, Neels H. The Belgian PCB/dioxin crisis -8 years later: An overview. Environ Toxicol Pharmacol. 2008;25(2):16470, http://dx.doi.org/10.1016/j.etap.2007.10.003.

14. Bertazzi PA, editor. Disasters, natural and technological. In: Stellman JM, editor-in-chief. Encyclopedia of Occupational Health and Safety. Geneva: International Labor Organization; 2011.

15. Sabbioni G, Wesp H, Lewalter J, Rumler R. Determination of isocyanate biomarkers in construction site workers. Biomarkers. 2007;12(5):468-83, http://dx.doi.org/10.1080/ 13547500701395636.

16. Beyerbach A, Farmer PB, Sabbioni G. Biomarkers for isocyanate exposure: Synthesis of isocyanate DNA adducts. Chem Res Toxicol. 2006;19(12):1611-8, http://dx.doi.org/10. 1021/tx0600853.

17. Kimmerle G, Eben A. [On the toxicity of methylisocyanate and its quantitative determination in the air]. Arch Toxicol. 1964;20:235-41. German.

18. Klaassen CD. Casarett and Doull's toxicology: The basic science of poisons. 6th ed. New York (NY): McGrawHill; 2001. p. 1007.

19. Indian Council of Medical Research. Report on health effects of the toxic gas leak from the methyl 
isocyanate plant in Bhopal. New Delhi: The Council; 2004.

20. Broughton E. The Bhopal disaster and its aftermath: A review. Environ Health. 2005;4(1):6, http://dx.doi. org/10.1186/1476-069X-4-6.

21. Moore MM, Chua W, Charles KA, Clarke SJ. Inflammation and cancer: Causes and consequences. Clin Pharmacol Ther. 2010;87(4):504-8, http://dx.doi.org/10.1038/ clpt.2009.254.

22. Mantovani A. Molecular pathways linking inflammation and cancer. Curr Mol Med. 2010;10(4):369-73, http://dx.doi. org/10.2174/156652410791316968.

23. Khan S, Bhargava A, Pathak N, Maudar KK, Varshney S, Mishra PK. Circulating biomarkers and their possible role in pathogenesis of chronic hepatitis $\mathrm{B}$ and $\mathrm{C}$ viral infections. Indian J Clin Biochem. 2011;26(2):161-8, http:/dx.doi. org/10.1007/s12291-010-0098-7.

24. Mishra PK, Panwar H, Bhargava A, Gorantla VR, Jain SK, Banerjee $\mathrm{S}$, et al. Isocyanates induce DNA damage, apoptosis, oxidative stress and inflammation in cultured human lymphocytes. J Biochem Mol Toxicol. 2008;22(6):429-40, http://dx.doi.org/10.1002/jbt.20260.

25. Mishra PK, Bhargava A, Raghuram GV, Gupta S, Tiwari S, Upadhyaya R, et al. Inflammatory response to isocyanates and onset of genomic instability in cultured human lung fibroblasts. Genet Mol Res. 2009;8(1):129-43, http://dx.doi. org/10.4238/vol8-1gmr544.

26. Mishra PK, Bhargava A, Raghuram GV, Jatawa SK, Akhtar N, Khan S, et al. Induction of genomic instability in cultured human colon epithelial cells following exposure to isocyanates. Cell Biol Int. 2009;33(6):675-83, http://dx.doi. org/10.1016/j.cellbi.2009.03.008.

27. Mishra PK, Khan S, Bhargava A, Panwar H, Banerjee S, Jain SK, et al. Regulation of isocyanate-induced apoptosis, oxidative stress, and inflammation in cultured human neutrophils: Isocyanate-induced neutrophils apoptosis. Cell Biol Toxicol. 2010;26(3):279-91, http://dx.doi.org/10.1007/ s10565-009-9127-9.
28. Bhargava A, Punde RP, Pathak N, Dabadghao S, Desikan P, Jain A, et al. Status of inflammatory biomarkers in the population that survived the Bhopal gas tragedy: A study after 2 decades. Ind Health. 2010;48(2):204-8, http://dx.doi. org/10.2486/indhealth.48.204.

29. López-Armada MJ, Riveiro-Naveira RR, Vaamonde-García C, Valcárcel-Ares MN. Mitochondrial dysfunction and the inflammatory response. Mitochondrion. 2013;13(2): 106-18, http://dx.doi.org/10.1016/j.mito.2013.01.003.

30. Khan S, Raghuram GV, Bhargava A, Pathak N, Chandra DH, Jain SK, et al. Role and clinical significance of lymphocyte mitochondrial dysfunction in type 2 diabetes mellitus. Transl Res. 2011;158(6):344-59, http://dx.doi. org/10.1016/j.trsl.2011.08.007.

31. Bhargava A, Raghuram GV, Pathak N, Varshney S, Jatawa SK, Jain D, et al. Occult hepatitis $\mathrm{C}$ virus elicits mitochondrial oxidative stress in lymphocytes and triggers PI3kinase-mediated DNA damage response. Free Radic Biol Med. 2011;51(9):1806-14, http://dx.doi.org/10.1016/j.freeradbiomed.2011.08.009.

32. Bhargava A, Khan S, Panwar H, Pathak N, Punde RP, Varshney S, et al. Occult hepatitis B virus infection with low viremia induces DNA damage, apoptosis and oxidative stress in peripheral blood lymphocytes. Virus Res. 2010;153(1): 143-50, http://dx.doi.org/10.1016/j.virusres.2010.07.023.

33. Khan S, Raghuram GV, Pathak N, Jain SK, Chandra DH, Mishra PK. Impairment of mitochondrial-nuclear cross talk in neutrophils of patients with type 2 diabetes mellitus. Indian J Clin Biochem. 2014;29(1):38-44, http://dx.doi. org/10.1007/s12291-013-0321-4.

34. Mishra PK, Raghuram GV, Panwar H, Jain D, Pandey H, Maudar KK. Mitochondrial oxidative stress elicits chromosomal instability after exposure to isocyanates in human kidney epithelial cells. Free Radic Res. 2009;43(8):718-28, http://dx.doi.org/10.1080/10715760903037699.

35. Raghuram GV, Pathak N, Jain D, Pandey H, Panwar H, Jain K, et al. Molecular characterization of isocyanate-induced male germ line genomic instability. J Environ Pathol 
Toxicol Oncol. 2010;29(3):213-34, http://dx.doi.org/10.1615/ JEnvironPatholToxicolOncol.v29.i3.50.

36. Panwar H, Jain D, Khan S, Pathak N, Raghuram GV, Bhargava $\mathrm{A}$, et al. Imbalance of mitochondrial-nuclear cross talk in isocyanate mediated pulmonary endothelial cell dysfunction. Redox Biol. 2013;1(1):163-71, http://dx.doi. org/10.1016/j.redox.2013.01.009.

37. Jantzen K, Roursgaard M, Desler C, Loft S, Rasmussen LJ, Møller P. Oxidative damage to DNA by diesel exhaust particle exposure in co-cultures of human lung epithelial cells and macrophages. Mutagenesis. 2012;27(6):693-701, http:// dx.doi.org/10.1093/mutage/ges035.

38. Jain D, Pathak N, Khan S, Raghuram GV, Bhargava A, Samarth R, et al. Evaluation of cytotoxicity and anticarcinogenic potential of Mentha leaf extracts. Int J Toxicol. 2011;30(2):225-36, http://dx.doi.org/10.1177/109158181 0390527.

39. Mishra PK, Raghuram GV, Bhargava A, Ahirwar A, Samarth R, Upadhyaya R, et al. In vitro and in vivo evaluation of the anticarcinogenic and cancer chemopreventive potential of a flavonoid-rich fraction from a traditional Indian herb Selaginella bryopteris. Br J Nutr. 2011;106(8):1154-68, http:// dx.doi.org/10.1017/S0007114511001498.

40. Pathak N, Khan S, Bhargava A, Raghuram GV, Jain D, Panwar H, et al. Cancer chemopreventive effects of the flavonoid-rich fraction isolated from papaya seeds. Nutr Cancer. 2014;66(5):857-71, http://dx.doi.org/10.1080/01635581. 2014.904912.

41. Durovic B, Spasic-Jokic V, Durovic B. Influence of occupational exposure to low-dose ionizing radiation on the plasma activity of superoxide dismutase and glutathione level. Vojnosanit Pregl. 2008;65(8):613-8, http://dx.doi.org/10.2298/ VSP0808613D.

42. Gerberick GF, Aleksic M, Basketter DA, Schultz TW. Chemical reactivity measurement and the predictive identification of skin sensitisers. The report and recommendations of ECVAM Workshop 64. Altern Lab Anim. 2008;36(2): $215-42$.
43. Miyata K, Kobori A, Seio K, Sekine M. Hybridization ability and base pair geometry of modified deoxycytidine derivatives having a 4- $\mathrm{N}$-carbamoyl group. Nucleic Acids Res. 2002;(2):161-2, http://dx.doi.org/10.1093/nass/2.1.161.

44. Mishra PK, Gorantla VR, Akhtar N, Tamrakar P, Jain SK, Maudar KK. Analysis of cellular response to isocyanate using $\mathrm{N}$-succinimidyl $\mathrm{N}$-methylcarbamate exposure in cultured mammalian cells. Environ Mol Mutagen. 2009;50(4): 328-36, http://dx.doi.org/10.1002/em.20469.

45. Bartek J, Lukas J. DNA damage checkpoints: From initiation to recovery or adaptation. Curr Opin Cell Biol. 2007;19(2):238-45, http://dx.doi.org/10.1016/j.ceb. 2007.02.009.

46. Panwar H, Raghuram GV, Jain D, Ahirwar AK, Khan S, Jain SK, et al. Cell cycle deregulation by methyl isocyanate: Implications in liver carcinogenesis. Environ Toxicol. 2014;29(3):284-97, http://dx.doi.org/10.1002/tox.21757.

47. Raghuram GV, Pathak N, Jain D, Panwar H, Pandey H, Jain SK, et al. Molecular mechanisms of isocyanate induced oncogenic transformation in ovarian epithelial cells. Reprod Toxicol. 2010;30(3):377-86, http://dx.doi.org/10.1016/j.repro tox.2010.05.087.

48. Delia D, Fontanella E, Ferrario C, Chessa L, Mizutani S. DNA damage-induced cell-cycle phase regulation of p53 and p21 waf1 in normal and ATM-defective cells. Oncogene. 2003;22(49):7866-9, http://dx.doi.org/10.1038/ sj.onc. 1207086.

49. Rizzolio F, Tuccinardi T, Caligiuri I, Lucchetti C, Giordano A. CDK inhibitors: From the bench to clinical trials. Curr Drug Targets. 2010;11(3):279-90, http://dx.doi. org/10.2174/138945010790711978.

50. Nojima H. G1 and S-phase checkpoints, chromosome instability, and cancer. Methods Mol Biol. 2004;280:3-49, http:// dx.doi.org/10.1385/1-59259-788-2:003.

51. Marchenko ND, Zaika A, Moll UM. Death signal-induced localization of 553 protein to mitochondria. A potential apoptotic signaling. J Biol Chem. 2000;275(21):16202-12, http://dx.doi.org/10.1074/jbc.275.21.16202. 
52. Mishra PK, Jatawa SK, Raghuram GV, Pathak N, Jain A, Tiwari A, et al. Correlation of aberrant expression of p53, Rad50, and cyclin-E proteins with microsatellite instability in gallbladder adenocarcinomas. Genet Mol Res. 2009;8(4):1202-10, http://dx.doi.org/10.4238/vol8-4gmr653.

53. Mishra PK, Raghuram GV, Jatawa SK, Bhargava A, Varshney $\mathrm{S}$. Frequency of genetic alterations observed in cell cycle regulatory proteins and microsatellite instability in gallbladder adenocarcinoma: A translational perspective. Asian Pac J Cancer Prev. 2011;12(2):573-4.

54. Vader G, Lens SM. The Aurora kinase family in cell division and cancer. Biochim Biophys Acta. 2008;1786(1):60-72, http://dx.doi.org/10.1016/j.bbcan.2008.07.003.

55. Ferguson RL, Maller JL. Centrosomal localization of cyclin E-CDK2 is required for initiation of DNA synthesis. Curr Biol. 2010;20(9):856-60, http://dx.doi.org/10.1016/ j.cub.2010.03.028.

56. Pacchierotti F, Eichenlaub-Ritter U. Environmental hazard in the aetiology of somatic and germ cell aneuploidy. Cytogenet Genome Res. 2011;133(2-4):254-68, http://dx.doi. org $/ 10.1159 / 000323284$.

57. Potapova TA, Zhu J, Li R. Aneuploidy and chromosomal instability: A vicious cycle driving cellular evolution and cancer genome chaos. Cancer Metastasis Rev. 2013;32(3-4): 377-89, http://dx.doi.org/10.1007/s10555-013-9436-6.

58. Tseng RC, Hsieh FJ, Hsu HS, Wang YC. Minimal deletion regions in lung squamous cell carcinoma: Association with abnormality of the DNA double-strand break repair genes and their applications on gene identification and prognostic biomarkers. Lung Cancer. 2008;59(3):332-9, http://dx.doi. org/10.1016/j.lungcan.2007.08.038.

59. Lu T, Finkel T. Free radicals and senescence. Exp Cell Res. 2008;314(9):1918-22, http://dx.doi.org/10.1016/j.yexcr. 2008.01.011.

60. Mirzayans R, Scott A, Andrais B, Pollock S, Murray D. Ultraviolet light exposure triggers nuclear accumulation of p21 (WAF1) and accelerated senescence in human normal and nucleotide excision repair-deficient fibroblast strains. J Cell Physiol. 2008;215(1):55-67, http://dx.doi. org/10.1002/jcp.21284.

61. Gosselin K, Martien S, Pourtier A, Vercamer C, Ostoich P, Morat L, et al. Senescence-associated oxidative DNA damage promotes the generation of neoplastic cells. Cancer Res. 2009;69(20):7917-25, http://dx.doi.org/10.1158/00085472.CAN-08-2510.

62. Hajkova P, Ancelin K, Waldmann T, Lacoste N, Lange UC, Cesari F, et al. Chromatin dynamics during epigenetic reprogramming in the mouse germ line. Nature. 2008;452(7189):877-81, http://dx.doi.org/10.1038/nature 06714 .

63. Chia N, Wang L, Lu X, Senut MC, Brenner C, Ruden DM. Hypothesis: Environmental regulation of 5-hydroxymethylcytosine by oxidative stress. Epigenetics. 2011;6(7):853-6, http://dx.doi.org/10.4161/epi.6.7.16461.

64. Koturbash I, Zemp FJ, Pogribny I, Kovalchuk O. Small molecules with big effects: The role of the microRNAome in cancer and carcinogenesis. Mutat Res. 2011;722(2): 94-105, http://dx.doi.org/10.1016/j.mrgentox.2010.05.006.

65. Kawanishi S, Oikawa S. Mechanism of telomere shortening by oxidative stress. Ann N Y Acad Sci. 2004;1019:278-84, http://dx.doi.org/10.1196/annals.1297.047.

66. Freund A, Orjalo AV, Desprez P-Y, Campisi J. Inflammatory networks during cellular senescence: Causes and consequences. Trends Mol Med. 2010;16(5):238-46, http://dx.doi. org/10.1016/j.molmed.2010.03.003.

67. Mishra PK, Raghuram GV, Jain D, Jain SK, Khare NK, Pathak N. Mitochondrial oxidative stress-induced epigenetic modifications in pancreatic epithelial cells. Int J Toxicol. 2014;33(2):116-29, http://dx.doi.org/10. $1177 / 1091581814524064$.

68. Raghuram GV, Mishra PK. Stress induced premature senescence: A new culprit in ovarian tumorigenesis? Indian J Med Res. 2014;140 Suppl:S120-9.

69. Mishra PK, Bunkar N, Raghuram GV, Khare NK, Pathak N, Bhargava A. Epigenetic dimension of oxygen radical injury in spermatogonial epithelial cells. Reprod 
Toxicol. 2015;52:40-56, http://dx.doi.org/10.1016/j.reprotox. 2015.02.006.

70. Mishra PK, Dabadghao S, Modi GK, Desikan P, Jain A, Mittra I, et al. In utero exposure to methyl isocyanate in the Bhopal gas disaster: Evidence of persisting hyperactivation of immune system 2 decades later. Occup Environ Med. 2009;66(4):279, http://dx.doi.org/10.1136/oem.2008.041517.

71. Mishra PK, Bhargava A, Pathak N, Desikan P, Maudar KK, Varshney S, et al. Molecular surveillance of hepatitis and tuberculosis infections in a cohort exposed to methyl isocyanate. Int J Occup Med Environ Health. 2011;24(1):94-101, http://dx.doi.org/10.2478/s13382-011-0006-2.

72. Punde RP, Bhargava A, Varshney S, Pathak N, Shrivastava M, Mishra PK. Ascertaining the prevalence of occult hepatitis B virus infection in voluntary blood donors: A study from Central India. Indian J Pathol Microbiol. 2011;54(2): 408, http://dx.doi.org/10.4103/0377-4929.81592.

73. Bhargava A, Punde R, Varshney S, Pathak N, Mishra PK. A novel FRET probe-based approach for identification, quantification, and characterization of occult $\mathrm{HCV}$ infections in patients with cryptogenic liver cirrhosis. Indian J Pathol Microbiol. 2011;54(2):420-1, http://dx.doi. org/10.4103/0377-4929.81609.

74. Khan S, Bhargava A, Pathak N, Maudar KK, Varshney S, Mishra PK. Circulating biomarkers and their possible role in pathogenesis of chronic hepatitis $\mathrm{B}$ and $\mathrm{C}$ viral infections. Indian J Clin Biochem. 2011;26(2):161-8, http://dx.doi. org/10.1007/s12291-010-0098-7.

75. Mishra PK, Bhargava A, Khan S, Pathak N, Punde RP, Varshney S. Prevalence of hepatitis $\mathrm{C}$ virus genotypes and impact of $\mathrm{T}$ helper cytokines in achieving sustained virological response during combination therapy: A study from Central India. Indian J Med Microbiol. 2010;28(4):358-62, http://dx.doi.org/10.4103/0255-0857.71813.

76. Bhargava A, Pathak N, Varshney S, Shrivastava M, Mishra PK. Molecular detection of window phase hepatitis $\mathrm{C}$ virus infection in voluntary blood donors and health care workers in a cohort from central India. Indian J Community Med. 2014;39(1):51-2, http://dx.doi.org/10.4103/ 0970-0218.126362.

77. Bhargava A, Mishra D, Banerjee S, Mishra PK. Dendritic cell engineering for tumor immunotherapy: From biology to clinical translation. Immunotherapy. 2012;4(7):703-18, http://dx.doi.org/10.2217/imt.12.40.

78. Bhargava A, Mishra D, Khan S, Varshney SK, Banerjee S, Mishra PK. Assessment of tumor antigen-loaded solid lipid nanoparticles as an efficient delivery system for dendritic cell engineering. Nanomedicine (Lond). 2013;8(7):1067-84, http://dx.doi.org/10.2217/nnm.12.164.

79. Bhargava A, Mishra D, Banerjee S, Mishra PK. Engineered dendritic cells for gastrointestinal tumor immunotherapy: Opportunities in translational research. J Drug Target. 2013;21(2):126-36, http://dx.doi.org/10.3109/106118 6X.2012.731069.

80. Bhargava A, Bunkar N, Khare NK, Mishra D, Mishra PK. Nanoengineered strategies to optimize dendritic cells for gastrointestinal tumor immunotherapy: From biology to translational medicine. Nanomedicine (Lond). 2014;9(14): 2187-202, http://dx.doi.org/10.2217/nnm.14.115.

This work is available in Open Access model and licensed under a Creative Commons Attribution-NonCommercial 3.0 Poland License - http://creativecommons.org/ licenses/by-nc/3.0/pl/deed.en. 